\title{
Living with diabetes: quality of care and quality of life
}

\author{
This article was published in the following Dove Press journal: \\ Patient Preference and Adherence \\ 20 January $201 \mathrm{I}$ \\ Number of times this article has been viewed
}

\section{Pilar Isla Pera}

Department of Public Health Nursing, Mental and Mother and Child Health, University of Barcelona, Spain
Correspondence: Pilar Isla Pera

EUI, Campus de Ciències de la Salut de Bellvitge, L'Hospitalet de llobregat 08907, Barcelona, Spain

Email pisla@ub.edu
Background: The aim of this research was to characterize the experience of living with diabetes mellitus (DM) and identify patients' opinions of the quality of care received and the results of interventions.

Methods: A descriptive, exploratory evaluation study using qualitative methodology was performed. Participants consisted of 40 adult patients diagnosed with DM and followed up in a public hospital in Barcelona, Spain. A semistructured interview and a focus group were used and a thematic content analysis was performed.

Results: Patients described DM as a disease that is difficult to control and that provokes lifestyle changes requiring effort and sacrifice. Insulin treatment increased the perception of disease severity. The most frequent and dreaded complication was hypoglycemia. The main problems perceived by patients affecting the quality of care were related to a disease-centered medical approach, lack of information, limited participation in decision-making, and the administrative and bureaucratic problems of the health care system.

Conclusion: The bureaucratic circuits of the health care system impair patients' quality of life and perceived quality of care. Health professionals should foster patient participation in decision-making. However, this requires not only training and appropriate attitudes, but also adequate staffing and materials.

Keywords: diabetes mellitus, health care quality, quality of life, qualitative research

\section{Introduction}

People with diabetes mellitus (DM) live with an incurable disease that requires not only drug therapy and blood glucose control, but also a healthy lifestyle and demanding changes in cultural patterns. ${ }^{1}$ This situation may have a deep psychological impact on affected individuals and increase their perception of a poor quality of life. ${ }^{2} \mathrm{DM}$ is one of the chronic diseases that frequently affects perception of health-related quality of life (HR-QOL), ${ }^{3,4}$ and is often associated with depression. This is, in turn, related to poor adherence to treatment, and to increased morbidity and mortality. ${ }^{4}$

HR-QOL is an interesting subjective concept because it provides information, independently of clinical data, on how the patient feels. ${ }^{5} \mathrm{HR}-\mathrm{QOL}$ is frequently used as a synonym for self-perceived health, which has been shown to be useful in predicting morbidity and mortality. ${ }^{6-8}$ However, HR-QOL questionnaires have some limitations because it is difficult to adapt them to the patient's context and to measure complex physical, psychological, and functional variables through a simple numerical evaluation. Moreover, HR-QOL instruments only evaluate the dimensions that patients 
experience directly, and exclude other variables that also affect their health, such as certain biological and environmental characteristics. ${ }^{9}$

Several qualitative studies have documented the experience of living with diabetes and the existence of beliefs and perceptions that allow us to understand how people cope with the disease. ${ }^{10-15}$ Qualitative investigation allows researchers to gain access to the world of emotions, feelings, and daily experiences, and insight into the impact of advanced technologies on patients, their facilities, and the social milieu of the individuals involved. This type of research also aids reflection on the social role of health professionals. Listening to the patient's account of their suffering can also help health professionals to be more human and genuine. ${ }^{16}$ This study aimed to characterize the experience of living with DM and to identify patients' opinions of health care received and the effects of health care interventions on their quality of life.

\section{Methods}

We performed a descriptive, exploratory evaluation study using a qualitative approach from a critical perspective because the social construction of reality begins to emerge through the reflective action of individuals and communities, and knowledge leads to action. ${ }^{17}$ Intentional sampling was performed, and included all groups representative of patients (gender, age, type of diabetes, and treatment). Forty adult patients with DM followed up in centers from distinct health care levels within the Barcelona public health system were selected. Twenty-six semistructured individual interviews were performed, and two focus groups composed of seven subjects each were conducted. The author conducted all interviews and focus groups in private offices within the health care institutions. The focus groups consisted of patients with type $1 \mathrm{DM}$. The focus group technique was discarded for people with type $2 \mathrm{DM}$ because the sample was obtained from different core areas of primary health care and it was easier to recruit individual patients to form groups. In contrast, patients with type $1 \mathrm{DM}$ came from two tertiary hospitals, were younger, and were used to participating in group sessions. The initial script was the same for the interview and focus groups. The interviews lasted approximately 30 minutes and the focus groups lasted 1.5 hours. Both the interviews and the focus groups were recorded on audiotape and transcribed verbatim after informed consent was obtained from all participants. The criterion of data saturation ${ }^{18}$ was used to establish the number of informants. The interview format was nondirective. Questions were open-ended, broad, and presented in a flexible manner. The investigator made an effort to acknowledge her assumptions of the phenomenon under study and to take into account the potential impact of her subjective perspective on the data. The investigator took part in a reflexive process during which she recorded her presuppositions derived from the literature and her personal views. These strategies were used in an effort to reduce bias and to gain a thorough understanding of the phenomenon under study that was as representative as possible of the participants' perspectives. ${ }^{19}$ Data were analyzed using content analysis and constant comparison following the method proposed by Miles and Huberman, ${ }^{20}$ and consisted of data reduction, data display, and conclusion drawing/verification. A content analysis was performed and cognitive maps were designed to facilitate selection and to identify any interrelationships between the most important concepts and categories. To improve the validity of the study, the information obtained was fed back to the informants at the end of the interview and focus groups. Complementary variables consisted of age, gender, type of diabetes, treatment, presence of acute or chronic complications known to the patient, and time since diagnosis of DM.

\section{Results}

Sociodemographic and clinical data are shown in Table 1. Three categories were established in the qualitative data analysis, ie, living with DM, quality of health care, relationship between health professionals and users, and quality of health care resources and service infrastructure.

\section{Living with diabetes}

Patients portrayed DM as a disease that is difficult to control and that leads to a change in lifestyle, requiring effort and sacrifice. Affected individuals used the popular concept of "sugar" to refer to type $2 \mathrm{DM}$ treated with oral antidiabetic drugs and the taxonomy of diabetes to refer to insulintreated type 1 or type $2 \mathrm{DM}$, revealing the perception of greater severity and complexity. “At the beginning, it didn't affect me because I only had high blood sugar but when I got diabetes and had to inject insulin I was very worried; diabetes changed my life" (from a 71-year-old man with type $2 \mathrm{DM}$ ).

The most common and dreaded complication of the disease was hypoglycemia. Some patients reported that fear of hypoglycemia stopped them sleeping properly, working normally, driving, or going out with friends. Anxiety about chronic complications was only reported by patients with 
Table I Sociodemographic and clinical data for informants

\begin{tabular}{lll}
\hline Gender & Men & 18 \\
& Women & 22 \\
Age (years) & $54.2 \pm$ I7.5 (range 20-82) & \\
Type of DM & DMI & 14 \\
Treatment of DM & DM2 & 26 \\
& Oral antidiabetic agents & 19 \\
& Oral antidiabetic & 1 \\
& agents + insulin & 16 \\
& Insulin & 4 \\
Time since diagnosis & Continuous insulin & \\
of DM (years) & infusion pump & \\
Presence of acute & $9.88+7.8$ & 28 \\
complications & (range 0.5-30) & 8 \\
Presence of chronic complications & Hypoglycemia & 2 \\
known by the patient & Retinopathy & I \\
\hline
\end{tabular}

Abbreviations: DM, diabetes mellitus; DMI, type I diabetes mellitus; DM2, type 2 , diabetes mellitus

type $1 \mathrm{DM}$ and referred to retinopathy. There was no visible stigma attached to DM, but some patients felt threatened and consequently hid their disease when seeking work, applying for a driving license, or when they were with friends or casual sexual partners. Beauty, youth, being "fit", and productivity were important shared values and were projected to the interviewees, encouraging the perception of a difference from "healthy" people and consequently the development of stigma:21 "If you say you are diabetic, you are eliminated from some selection processes" (from a 39-year-old man with type $1 \mathrm{DM})$. Many patients feared transmitting the disease to their children, generating worry when planning a family and some anxiety if they already had children: "I was too scared to get pregnant and have a diabetic child. My daughter is eight years old and she's well, but I always think, 'Will she be diabetic in the future?' " (from a 41-year-old woman with type $1 \mathrm{DM})$. Underlying this etiologic concept was the idea of fate, because diabetes was perceived as being rooted in their lineage and transmitted through the family blood. ${ }^{22}$

Participating patients treated with a continuous insulin infusion pump had begun their treatment one month earlier. The patients were satisfied with the training program and hoped that the continuous insulin infusion pump would stabilize their blood glucose levels and give them peace of mind. However, they described the continuous insulin infusion pump as a foreign object stuck to their bodies, which was annoying because the devices were heavy and uncomfortable to sleep with, when bathing or working, or when taking part in leisure activities: "Injections are much better because afterwards you can forget about them" (from a 36-year-old woman with type $1 \mathrm{DM}$ ). The pump must be carried at all times, and was a constant reminder to patients of their disease and insulin dependence.

Some participants confessed that they did not follow recommendations, but most tried to find a balance between medical demands and maintaining a lifestyle that did not involve excessive sacrifice or create major difficulties with other people in their environment. Diet was a notable source of conflict because of the difficulties of modifying habits, adapting to the sociocultural environment, and financial considerations: "The diet is expensive. When I go out with friends, I can't just ask for a large plate of pasta and nothing else like they do" (from a 20-year-old woman with type $2 \mathrm{DM}$ ). All patients agreed that they broke their diet because " . . . it's the only way to adapt and have the closest thing to a normal life when you go out with friends, are traveling or celebrating something and, sometimes, to give yourself a treat".

\section{Perceived quality of life by health professionals versus users}

Patients valued medical knowledge highly, and considered this to be superior to any other type of knowledge, although this belief did not prevent many informants from seeking alternative complementary remedies.

Patients managed in primary care valued health professionals positively but many criticized their medical care. They complained of the biomedical focus, waiting times, shortness of consultations, and frequent changes of doctor: "The doctor is always in a hurry, he tells you what you have to take and if you have to have a test and then sends you to the nurse so that she can explain things to you" (from a 54-year-old man with type $2 \mathrm{DM}$ ). Nevertheless, they recognized that many problems were due to organizational factors and lack of resources: "Quality is not as high as it should be but that's because of the lack of time and resources" (from a 64-year-old woman with type $2 \mathrm{DM}$ ). Starting insulin treatment increased the perception of risk and led to greater demands: "Primary care doctors look at DM in the same way they would look at a leg. When you need insulin, it would be better if a specialist saw you" (from a 72-year-old man with type $2 \mathrm{DM}$ ). Most patients found primary care nurses to be kind, and said they provided a great deal of information, but some found this information to be excessive and hastily delivered. Sometimes the information was poorly understood and not well adapted to the patient's needs: "I know she's tell- 
ing me for my own good, but I don't listen to her. She always tells me a ton of things I have to do ... but I don't do anything. They don't realize that I can't because I'm very old" (from a 73-year-old woman with type $2 \mathrm{DM}$ ).

Patients managed in specialized hospital units were satisfied with the health care received, although they reported individual differences, mainly among physicians. The informants acknowledged that when they had problems, they were seen rapidly but, as in primary care, they believed that physicians were only interested in glycemia and its complications, and not in the patient as a person, and that they provided little information. "The doctor gives you the results, tells you whether you are all right or not, and so on ... It's true that if you have a problem and telephone, they'll talk to you but the doctors explain very little on their own initiative. It's the nurse who gives you the information but you don't always go to the nurse" (from a 36-year-old man with type $1 \mathrm{DM})$. Some participants felt that doctors blamed patients for alterations in glycemia control without stopping to think of the causes and without taking into account individual physical, psychological, and social circumstances: "Sometimes it's not a matter of whether you follow all the steps. Doing the same thing, one day you have a blood glucose level of $200 \mathrm{mg} / \mathrm{dL}$. I always ask myself 'what's happening to me today?' But I don't know. The feeling I have is that the doctors think that you must have done something wrong ... They follow their manual" (from a 37 -year-old woman with type $1 \mathrm{DM}$ ). The most highly valued health professionals were patient education nurses working in specialized hospital diabetes units, although patients complained of the lack of continuity in patient education: "I wouldn't give them a 10 because that's for excellence but I would give them a 9. The problem is that they only see you at the beginning, although if I ring them and ask them something they're always helpful" (from a 39-year-old man with type $1 \mathrm{DM})$.

\section{Resources and service infrastructure}

The most frequent criticisms related to dispensation of materials, the schedule for consultations and complementary tests, and bureaucratic circuits. Patients with type 1 DM managed in primary care complained of restriction of blood glucose test strips, waiting times for some tests, and lack of free cover for diabetic lancets, podiatrists, and dentists: "Sometimes I jab myself with a sewing needle because a box of 20 costs me more than 7 Euros and my husband's pension ..." (from a 64-year-old woman with type $2 \mathrm{DM})$.
The most critical patients were those with type $1 \mathrm{DM}$ managed in specialized units. The Catalan system requires them to go to the primary care center for dispensation of materials, which they interpret as an unnecessary circuit that is time-consuming during working hours and involves bureaucratic procedures with distinct health professionals and administrative staff not connected with their health problem and with little understanding of it: "When my doctor changed my insulin or I need another box, I have to make an appointment with the primary care doctor who doesn't know that form of insulin and doesn't even ask about it. He brings up screens on his computer until he finds it and all he does is change a few parameters in a database so that he can give it to me. That's all, but I've lost the whole morning" (from a 39-year-old man with type $1 \mathrm{DM})$.

Interviewees also complained of the lack of coordination that required them to go on different days for tests that could be performed on the same day and of inappropriate schedules: "They never adapt to your needs. They give you a time for a blood test at 11 o'clock in the morning or even later, even though you tell them that you have to inject your insulin and have breakfast" (from a 36-year-old man with type 1 DM). The circuits for material dispensing and scheduling of appointments and tests increased patients' perception of social vulnerability: "The dispensation of material and the schedule of appointments and tests are appalling. They make you go at times when you can't because of work. There's a domino effect that harms us because the schedule increases prejudices against hiring us and, if you have work, you can be fired or passed over for promotion" (from a 39-year-old man with type $1 \mathrm{DM}$ ). Participants also believed that the number of appointments and checkups was lower than that recommended by international scientific societies, due the pressure of waiting lists that prevent appointments from being scheduled according to medical criteria: "The doctor tells you to come back within six months but there are no free appointments and it doesn't matter if you insist because everything's full up. They tell you ' ... that's the way it is ...' and give you an appointment for nine months' time" (from a 36-year-old man with type $1 \mathrm{DM}$ ).

Some patients believed that there is a conflict of interest between industry and research aimed at a cure or prevention of DM due to the monopoly they believed some companies have on treatment and control of the disease: "Curing diabetes is not impossible. When you think of the things that can be done! But a lot of money is involved in diabetes treatment and many international companies and many people get a lot out of it. I'm convinced that they could do a lot more but they just aren't interested" (from a 36-year-old woman with 
type $1 \mathrm{DM})$. Patients' requirements of health professionals and health managers are shown in Table 2.

\section{Discussion}

Diagnosis of DM and recognition of the disease is manifested not only by organic and functional alterations, but also by a process demanding lifestyle changes. In their accounts, in addition to physical problems, patients in this survey expressed feelings and emotions that describe the drama of the sick person, and how DM, its treatments, science, and the health system affect their quality of life. They also describe their needs, expectations, and demands, and the relationship they would like to have with health professionals. However, this type of narration does not occur in the context of health care.

The greater perception of disease severity associated with insulin treatment is in agreement with other studies reporting that dependence on treatment and the risks of insulin creates rejection and dread. ${ }^{11-15}$ Insulin is rejected by many patients because they believe this therapy has pernicious adverse effects, including blindness, ${ }^{12-14}$ fatigue, weakness, and loss of stamina, ${ }^{11-23}$ and should only be used when the person is extremely sick. ${ }^{11,12}$ These beliefs should be taken into account by health professionals, because the symbolic component of insulin treatment affects its perception and acceptance by patients. Most participants did not show concern about the chronic complications of DM, although some knew that they were affected. This lack of concern could be due to insufficient information, to a perception of lack of vulnerability, a coping strategy to reduce anxiety, ${ }^{24}$ lack of initial symptoms (because self-diagnosis and perception of risk are related to visible signs and symptoms), and to timing (because the harmful consequences of poor diabetes control become apparent only in the long term). ${ }^{24,25}$

Most interviewees had difficulty in following a strict treatment regimen. Patients share some objectives with their health professionals (maintaining blood glucose control, avoiding complications) but also have other physical, psychological, and social needs that can conflict with the objectives of health care professionals. Nurses, in particular, aim to get the patient to undertake "self-management" as a way of promoting autonomy and independence. However, some patients believed that DM limits their freedom and, for these individuals, personal freedom, without excessive rules and restrictions imposed by treatment, is the only way to achieve autonomy and independence. Many patients, especially older ones with type $2 \mathrm{DM}$, view management of their disease differently from health professionals. For patients, good diabetes control equates with not having symptoms and being able to perform their normal activities, whereas for health professionals, control is evaluated through specific algorithms that bear little relation to the patient's experience. The perception of not being understood and sometimes blamed for poor diabetes control creates unease and distrust, and leads to health professionals being considered as inflexible scientists who "follow the manual" instead of using their knowledge and experience to assess individual situations. The qualities in health professionals most highly valued by

Table 2 Patient requirements of health professionals and administrators

Requirements of health professionals

- Treatment should be individualized because each body and each person is different

- Physicians should spend more time with patients and talk and express their opinions less

- Nurses should show greater patience; controlling diabetes is not as easy as they think

- Education should be continuous and talks and workshops should be continually organized

- Patients should not be asked to do the impossible without bearing in mind their opinions and possibilities

- Professionals should not lecture patients; patients are adults, know what they want, and should be respected

- The public should not be given a catastrophic view of diabetes mellitus; this picture is harmful to patients socially and occupationally
Requirements of health administrators

- Number of physicians and nurses should be increased

- Position of case manager should be created in all hospitals to coordinate investigations in the least possible time and to consider the needs of each patient individually

- Physicians should be changed less frequently because they never get to know the patient

- Diabetes units should be created in primary health centers with specialized physicians and nurses

- Necessary material should be provided with individualized follow-up of needs and use of materials

- Processes should be simplified; modern computerized or technological systems and computerized prescriptions or magnetic cards should be introduced so that pharmacies can dispense all the material required at any time of day

- Budgets should be controlled so that patients are not told that they cannot be given strips or that they have to monitor themselves less often

- Research to cure diabetes or improve treatment and quality of life in affected individuals should be stimulated 
patients were their training, professional experience, and empathy. As in other studies, ${ }^{26-31}$ satisfaction with health care reflected the patients' perception that the therapeutic relationship was characterized by dialog, respect, agreement, understanding, concern for the emotional and social problems caused by the disease, and a degree of collusion in occasionally breaking a few rules.

Complaints about not being listened to and lack of respect and trust were numerous, and patients linked these deficiencies directly to quality of health care. Patients complained of the need for better administrative and bureaucratic circuits and for health professionals who are effective, kind, and respectful, and who know how to listen and provide information without being authoritarian. Users, especially the young, required information on new developments in research aimed at curing DM or treatment to maintain realistic hope. Many informants believed that there was an absence of interaction that would allow an exchange of knowledge and active patient participation in decision-making. These results are similar to those of other studies that have reported problems with communication and the biomedical focus, independently of the country in which the studies were performed, ${ }^{32-36}$ as well as patients' need to have their experience recognized, ${ }^{37-40}$ given that $90 \%$ of the measures to control blood glucose are performed by the patients or their families, who frequently have to make decisions in real time in response to specific situations. The difference in the present study is that users did not only expressed their needs, but also demanded their rights. This finding was common to all the interviewees, but was more openly expressed by those with type $1 \mathrm{DM}$ and by younger patients. Greater vociferousness in demanding their rights could be due to an increase in basic training and diabetes education among patients and their families, the full implementation of democracy in Spain, developments in the concept of health and public discourse on patients' rights, and could also be a form of exercising empowerment. Patients and patient associations reject health professionals' paternalistic and authoritarian attitudes and demand therapeutic effectiveness, dialog, participation in decisionmaking, and respect, even when they do not wish to comply with recommendations.

A much less studied issue is the relationship between quality of life and the administrative and bureaucratic processes of the health system. In this study, the greatest distress in patients with type $1 \mathrm{DM}$ and the largest number of complaints about quality of health care referred to these factors, because they increased patients' perception of social vulnerability, and directly affected their quality of life and expectations of the future.

This study has some limitations. The advanced age of some patients with type $2 \mathrm{DM}$ and the geographic distribution of the consultations studied made it difficult to carry out the focus group technique that encourages interaction and increases the individual's reactions. Second, it would have been interesting to gather data from different sources, such as field notes and focus groups, which might have enhanced the richness, breadth, and depth of the data and the worth of the final interpretations. ${ }^{19}$ The qualitative methodology used in the present study does not allow the results to be extrapolated to a broader sample of persons with DM, but is appropriate to examine patients' accounts of their disease, the problems it generates in their lives, and to identify their perceptions of quality of care. The results transcend the strictly individual experience of the interviewees, and enable reflection on the problems of the health care provided for people with DM. Understanding the patient's existential framework and their experience of DM are key factors for being able to create new strategies for intervention and improvement. ${ }^{41}$

In conclusion, the results of this study indicate the main problems perceived by patients with DM that affect their quality of life. These problems concern the difficulty of following a strict treatment regimen for the rest of their lives, fear of hypoglycemia, a disease-centered health care model lacking dialog and participation in decision-making, and bureaucratic and administrative circuits that hamper the integration of the disease into patients' social and occupational lives. These findings are not exclusive to the study setting or to DM, but reflect the biopositivist perspective that characterizes modern medicine. ${ }^{42-44}$ Despite the efforts of some health care professionals and the theoretical development of the health care model and the health care professional-user relationship, the model that still predominates in health care is a biomedical one favoring study of the body as an object, allows expert knowledge to dominate in the therapeutic relationship, and grants decision-making power to health professionals, based on visible symptoms and signs of the disease. To improve quality of care, more comprehensive health care is required that encompasses the physical, emotional, and social problems attributable to chronic disease because the biological focus is unable to meet all the patient's needs. ${ }^{45}$ Health professionals should encourage patient participation in decision-making and take bureaucratic and administrative processes into account, because these processes directly encourage stigma and affect quality of life in DM patients. 
Achieving this aim requires not only training programs and willingness, but also adequate human and material resources. A major source of conflict in the physician-patient relationship is the pressure of work, especially in primary care consultations. This situation leaves patients dissatisfied, and leads to burnout among professionals, ${ }^{30}$ brings the philosophy of the primary care center and family physicians into question, and compromises the effectiveness of the primary care reforms introduced in Spain in 1985. These results concerning the experience of living with diabetes are consistent with those of other qualitative studies, but there is still a dearth of data in the available literature on the impact of linking quality of care with quality of life. Future studies in this area are essential.

\section{Disclosure}

The author reports no conflict of interest in this work.

\section{References}

1. Isla Pera P, Moncho Vasallo J, Torras Rabasa A, Oppenheimer Salinas F, Fernández Cruz Pérez L, Ricart Brulles MJ. Quality of life in simultaneous pancreas-kidney transplant recipients. Clin Transplant. 2009;23:600-605.

2. Wallerstein N, Bernstein E. Empowerment education: Freire's ideas adapted to health education. Health Educ Q. 1988;15:379-394.

3. Chen HY, Baumgardner DJ, Rice JP. Health-related quality of life among adults with multiple chronic conditions in the United States, behavioral risk factor surveillance system, 2007. Prev Chronic Dis. 2011;8:A09.

4. Egede LE, Ellis C. Diabetes and depression: Global perspectives. Diabetes Res Clin Pract. 2010;87:302-312.

5. Aaranson NK. Methodologic issues in assessing the quality of life of cancer patients. Cancer. 1991;1:67(3 Suppl):844-850.

6. Kaplan G, Camacho T. Perceived health and mortality: A nine-year follow-up of a human population laboratory cohort. Am J Epidemiol. 1983;117:292-304.

7. Ifudu O, Paul HR. Effect of missed hemodialysis treatments on mortality in patients with end-stage renal disease. Nephron. 1998;79:385-386.

8. Kutner NG, Lin LS, Fielding B, Brogan D, Hall WD. Continued survival of older hemodialysis patients: Investigation of psychosocial predictors. Am J Kidney Dis. 1994;24:42-49.

9. Isla Pera P, Moncho Vasallo J, Torras Rabasa A, Oppenheimer Salinas F, Fernández Cruz Pérez L, Ricart Brulles MJ. Quality of life in simultaneous pancreas-kidney transplant recipients. Clin Transplant. 2009;23:600-605.

10. Parkerson GR, Gutman RA. Perceived mental health and disablement of primary care and end-stage renal disease patients. Int $J$ Psychiatry Med. 1997;:I27:33-45.

11. Isla pera $P$. The helthcare process of simultaneous pancreas and kidney transplantation. (doctoral thesis). Spain: Universidad de Alicante; 2006.

12. Hernández Ibarra E, Mercado Mártinez FJ. Chronic diseases from the perspective of social actors: A multicenter qualitative research. Book presentations II Iberoamerican Congress of Qualitative Health Research

13. Garro L. Narrative representations of chronic illness experience: Cultural models of illness, mind, and body in stories concerning the temporomandibular joint. Soc Sci Med. 1994;38:775-788.

14. Campos R. Nosotros los Curanderos. México: Nueva Imagen; 1997.
15. Torres López M. Blood and sugar. Representations of chronic diabetes patients in a suburb of Guadalajara, México (doctoral thesis). Tarragona, Spain: Universitat Rovira i Virgili; 1999.

16. Frank W. The Wounded Storyteller: Body, Illness and Ethics. Chicago, IL: University of Chicago Press; 1995.

17. Buendía Eisman L, Colas Bravo P. Madrid: McGraw-Hill; 1998.

18. Hammersley, M., \& Atkinson, P. Ethnography: Principles in practice, 3rd ed. London, UK: Routledge; 2007

19. Morrow SL. Quality and trustworthiness in qualitative research in counseling psychology. J Couns Psychol. 2005;52:250-260.

20. Miles M, Huberman M. Qualitative Data Analysis: An Expanded Sourcebook. Newbury Park, CA: Sage; 1994.

21. Goffman E. Estigma. La Identidad Deteriorada. 8th ed. Buenos Aires: Amorrortu Editores; 2001.

22. Boltanski L. As Classes Sociais e o Corpo. 4th ed. São Paulo: Paz e Terra; 2004

23. Cohen Marlene Z, Tripp T, Smith C, Soforoman B, Lively S. Explanatory models of diabetes: Patient practitioner variation. Soc Sci Med. 1994;38:59-66.

24. Isla Pera P, Moncho Vasallo J, Guasch Andreu O, Torras Rabasa A. Alignment of the Kübler-Ross grief cycle phases with the process of adaptation to type 1 diabetes mellitus. Endocrinol Nutr. 2008; 55:78-83.

25. Bayés R. SIDA y Psicología. Barcelona: Mártinez Roca; 1995.

26. Stevenson FA, Cox K, Britten N, Dundar Y. A systematic review of the research on communication between patients and health care professionals about medicines: The consequences for concordance. Health Expect. 2004; 7:235-245.

27. Naithani S, Gulliford M, Morgan M. Patients' perceptions and experiences of 'continuity of care' in diabetes. Health Expect. 2006;9: $118-129$.

28. Gulliford MC, Naithani S, Morgan M. Continuity of care and intermediate outcomes of type 2 diabetes mellitus. Fam Pract. 2007; 24:245-251.

29. Alazri MH, Neal RD. The association between satisfaction with services provided in primary care and outcomes in Type 2 diabetes mellitus. Diabet Med. 2003;20:486-490.

30. Bolaños E, Sarria-Santamera A. Perspective of patients on type-2 diabetes and their relationship with primary care health professionals: a qualitative study. Aten Primaria. 2003;32:195-202.

31. Crossley J, Davies H. Doctors' consultations with children and their parents: A model of competencies, outcomes and confounding influences. Med Educ. 2005;39:807-819.

32. Abdulhadi N, Al Shafaee M, Freudenthal S, Ostenson CG, Wahlström R. Patient-provider interaction from the perspectives of type 2 diabetes patients in Muscat, Oman: A qualitative study. BMC Health Serv Res. 2007;7:162.

33. Collins S. Explanations in consultations: The combined effectiveness of doctors' and nurses' communication with patients. Med Educ. 2005; 39:785-796.

34. Teutsch C. Patient-doctor communication. Med Clin North Am. 2003; 87:1115-1145.

35. Sofaer S, Crofton C, Goldstein E, Hoy E, Crabb J. What do consumers want to know about the quality of care in hospitals? Health Serv Res. 2005;40:2018-2036.

36. Trummer UF, Mueller UO, Nowak P, Stidl T, Pelikan JM. Does physician-patient communication that aims at empowering patients improve clinical outcome? A case study. Patient Educ Counsel. 2006;61:299-306.

37. Escudero-Carretero MJ, Fernández Fernández I, March-Cerdà JC. Physician/patient relationship in diabetes mellitus type 1 treatment. A qualitative study. Ate Primaria. 2006; 38:8-15. 
38. Escudero-Carretero MJ, Prieto-Rodríguez MA, Fernández-Fernández I, March-Cerdà JC. Expectations held by type 1 and 2 diabetes mellitus patients and their relatives: The importance of facilitating the healthcare process. Health Expect. 2007;10:337-349.

39. Curtis K, Liabo K, Roberts H, Barker M. Consulted but not heard: A qualitative study of young people's views of their local health service. Health Expect. 2004;7:149-156.

40. Kennedy I. Patients are experts in their own field. BMJ. 2003; 326:1276-1277.

41. Murphy E, Kinmonth AL. No symptoms, no problem? Patients' understandings of non-insulin dependent diabetes. Fam Pract. 1995; 12:184-192.

42. Zhu K, McKnight B, Stergachis A, Daling JR, Levine RS. Comparison of self-report data and medical records data: Results from a case-control study on prostate cancer. Int J Epidemiol. 1999;28:409-417.
43. Rothman I, Stanford JL, Kunyyuki A, Berger RE. Self-report of prostatitis and its risk factors in a random sample of middle-aged men. Urology. 2004;64:876-879.

44. Klungel OH, de Boer A, Paes AH, Seidell JC, Bakker A. Cardiovascular diseases and risk factors in a population-based study in The Netherlands: Agreement between questionnaire information and medical records. Neth J Med. 1999;55:177-183.

45. Guereiro Vieira da Silva D. Narrativas do vivir com diabetes mellitus: Experiencias pessoais e culturais. Série Teses em Enfermagem $\mathrm{n}^{\circ}$ 27. Trindade. Florianópolis; UFSC/Programa de Pos-Graduació em Enfermagem; 2001.

\section{Publish your work in this journal}

Patient Preference and Adherence is an international, peer-reviewed, open access journal focusing on the growing importance of patient preference and adherence throughout the therapeutic continuum. Patient satisfaction, acceptability, quality of life, compliance, persistence and their role in developing new therapeutic modalities and compounds to optimize clinical outcomes for existing disease states are major areas of interest. This journal has been accepted for indexing on PubMed Central. The manuscript management system is completely online and includes a very quick and fair peer-review system. Visit http://www.dovepress.com/ testimonials.php to read real quotes from published authors. 